\title{
Changes in the mesocarp of Annona cherimola Mill. 'Madeira' during postharvest ripening
}

\author{
Nereida Cordeiro $^{\mathrm{a}, *}$ Lúcilia Sousa $^{\mathrm{a}}$, Nélia Freitas ${ }^{\mathrm{a}}$, Manuela Gouveia $^{\mathrm{b}}$ \\ a Competence Centre for Exact Sciences and Engineering, University of Madeira, 9000-390 Funchal, Portugal \\ ${ }^{\mathrm{b}}$ Competence Centre of Life Sciences, University of Madeira, 9000-390 Funchal, Portugal
}

\section{A R T I C L E I N F O}

\section{Article history:}

Received 10 February 2013

Accepted 26 May 2013

\section{Keywords:}

Cherimoya

Chemical composition

Fruit ripening

Starch

Soluble sugars

Lipophilic extractives

\begin{abstract}
A B S T R A C T
Physicochemical changes during postharvest ripening of cherimoya (Annona cherimola Mill. 'Madeira'), were investigated to follow the principal modifications occurring during this process and to determine nutritional value. Fruit harvested at the mature green stage were analyzed during ripening using standard methods. Significant $(P<0.05)$ changes in chlorophyll, starch, titratable acidity, total free sugars and uronic acids were obtained, but no significant changes were found in ash, protein, lignin and lipid contents during ripening. The most obvious changes were chlorophyll degradation, an accentuated decrease of starch and an increase in total free sugars, with glucose the predominant sugar in the mesocarp, as revealed by GC analyses. Firmness loss was mainly attributed to depolymerization of pectin and lipid deterioration rather than hemicellulose degradation. Results also showed that the cherimoya variety evaluated in this study is a good source of minerals (mainly potassium), palmitic acid, linoleic acid, $\alpha$-linolenic acid and sitosterol.
\end{abstract}

(c) 2013 Elsevier B.V. All rights reserved.

\section{Introduction}

The consumption of tropical and subtropical fruit is increasing worldwide (FAO, 2012), with consumer demand for new tastes. The cherimoya (Annona cherimola Mill.) is a soft subtropical fruit well adapted to the edaphoclimatic conditions of Madeira Island. The main cultivars of cherimoya produced in Madeira have been analyzed in a previous study (Caldeira et al., 1995), which conferred to 'Madeira' as superior in commercial and organoleptic characteristics, giving it a high potential for commercialization in national and international markets. Fruit are harvested when they have turned from pale green to yellow-green, the areas between the few small conical protuberances have filled out or when skin gives a little to touch. Thus, the tender skin and the short shelf-life, 5-7 days, makes the fruit vulnerable to physical injuries after harvesting, during handling, transport and marketing, restricting its commercialization. These facts imply that producers have to harvest before fruit ripening. To extend the postharvest life of this fruit, they can be stored either at low temperature, which usually leads to chilling injury below $10^{\circ} \mathrm{C}$ (Alique et al., 1994), depending on the cultivar, or under controlled modified atmosphere (Alique and Oliveira, 1994). Although this is a common practice nowadays, it results in severe

\footnotetext{
* Corresponding author. Tel.: +351 291705 107; fax: +351 291705149

E-mail address: ncordeiro@uma.pt (N. Cordeiro).
}

loss of fruit quality in relation to texture, taste and flavor (Pareek et al., 2011).

In general, fruit ripening is complex and the mechanisms by which fruit soften during this process are unclear and subject to speculation. During ripening some modifications in the chemical composition, either by enzymatic or non-enzymatic processes (Brummell, 2006), lead to remarkable changes in fragrance, flavor and a decrease in pulp firmness. Decrease in fruit firmness is due, at least in part, to the disassembly of the cell walls which are a complex intertwining network containing cellulose/hemicelluloses embedded in an amorphous gelatinous matrix formed mainly by pectins and stabilized by (glyco) proteins and phenolics. For many fruit species, postharvest ripening is accompanied by an increase in pectin solubility and loss of neutral sugars mainly galactose, arabinose and mannose which is related to depolymerization of pectins (Manrique and Lajolo, 2004). Although the modifications of cell wall polysaccharides seem to be widespread among several fruit species, variations in cell wall composition could lead to differences in the softening process depending on the species.

In cherimoya, some investigations have been undertaken on fruit quality parameters to ascertain the changes taking place during postharvest ripening (Martinez et al., 1993; Gutiérrez et al., 2005; Goñi et al., 2007). However, as the chemical composition depends on the cultivar, environmental conditions and also on the ripe stage of the fruit, the present study aimed to evaluate the main chemical changes that occurs on the mesocarp of cherimoya 'Madeira' which are essentially related to fruit quality. This 
knowledge is important to understand the nutritional value and commercialization potential of this fruit and may help to interfere with the process of ripening in order to extend postharvest life.

\section{Materials and methods}

\subsection{Sample preparation and physical parameters}

Cherimoya (A. cherimola Mill. 'Madeira') fruit were harvested (early January) from trees in a commercial orchard in Faial (Madeira Island, Portugal). Fruit at mature green stage with no evidence of physical or pathological injuries were selected. Each fruit was carefully washed with sodium hypochlorite (2\%) to remove potential contaminants. Fruit were weighed at the beginning of the experiment and at the end of each storage period using a digital balance. The difference between initial and final fruit weight was considered as weight loss during that storage period and was expressed in percentage. The density of each cherimoya was determined by the ratio of weight and water volume displaced after fruit immersion into a measuring cylinder. Afterwards, lots of five fruit were randomly selected and stored at room temperature $\left(20-22^{\circ} \mathrm{C}\right)$ in a dimly-lit place. Every day after harvest, fruit were randomly chosen for physicochemical analyses. Fruit firmness was determined after removing the skin on two opposite sides at the middle of each fruit using a pressure-testing instrument (Model FT 327) fitted with an $11.3 \mathrm{~mm}$ cylindrical plunger. The force required to penetrate into the flesh was expressed in N. Penetration was carefully performed to avoid nearby seeds. Immediately, fruit were peeled (green peel was fully discarded), sliced, quick-frozen in liquid nitrogen and stored at $-80^{\circ} \mathrm{C}$. From each sample a fresh slice was used to measure fruit water content using a humidity balance (GibertiniEurotherm) at $105^{\circ} \mathrm{C}$. Frozen mesocarp samples were lyophilized, milled and stored in the dark under vacuum for further analyses. In storage the average humidity was approximately $5 \%$.

\subsection{Chemical analyses}

To determine chlorophyll content, $1 \mathrm{~g}$ of sample and $5 \mathrm{~mL}$ of acetone at $80 \%(\mathrm{v} / \mathrm{v})$ were homogenized with a vortex and submitted to ultrasound extraction for $5 \mathrm{~min}$ at $25^{\circ} \mathrm{C}$. Samples were then centrifuged (Biofuge Stratos, Heraeus) at $1600 \mathrm{rpm}$ for $5 \mathrm{~min}$. The supernatant was placed in a quartz cell and its absorbance was measured by an ultraviolet-visible spectrometer (UV-2401, Shimadzu), at $663 \mathrm{~nm}$ (chlorophyll $a$ ) and at $646 \mathrm{~nm}$ (chlorophyll $b$ ) using $80 \%$ acetone as blank solution. Chlorophyll analysis was performed in duplicate in a dimly light room and its content was determined according to the equation of Lichtenthaler (1987). Unless otherwise stated, chemical analyses were performed according to AOAC (2000). Ash content was determined by complete incineration of $1 \mathrm{~g}$ of mesocarp sample in a Nabertherm furnace at $600^{\circ} \mathrm{C}$ for $6 \mathrm{~h}$. Crude protein content was calculated by converting the nitrogen content $(N \times 6.4)$, determined by the Kjeldahl method in a Kjeldahl Selecta Alcodest still. The lignin content was determined using the Klason method (T 204 om-88). Titratable acidity was determined twice and the results expressed as citric acid equivalents. The content of uronic acids was obtained based on the method of $m$-phenylphenol with the galacturonic acid as standard. The iodine colorimetric method was used to measure starch content. Total free sugars (sucrose and reducing sugars) were determined according to Dubois et al. (1956), using glucose as the standard. The sugars monomers were determined by acid hydrolysis (Blakeney et al., 1983) followed by gas chromatography (GC), using a HP 5890 chromatograph equipped with a fused silica capillary column J\&W DB-225 ( $30 \mathrm{~m} \times 0.25 \mathrm{~mm}$ i.d.; $0.15 \mu \mathrm{m}$ film thickness). Before sample injection, calibration curves for rhamnose, fucose, arabinose, xylose, mannose, galactose and glucose were obtained using high purity commercial standards.

\subsection{Lipophilic extractives}

Milled mesocarp samples were extracted by Soxhlet with dichloromethane during $6 \mathrm{~h}$. Dichloromethane was selected as a specific solvent for lipophilic extractives isolation for analytical purposes. The solvent was evaporated to dryness and the amount of extracts determined by gravimetry. The lipophilic extractives were identified and quantified by gas chromatography-mass spectrometry (GC-MS) as described by Oliveira et al. (2006). Briefly, $20 \mathrm{mg}$ of each dried extract with a measured amount of internal standard was dissolved in $250 \mu \mathrm{L}$ of pyridine. After the addition of $250 \mu \mathrm{L}$ of bis(trimethylsilyl)trifluoroacetamide and $50 \mu \mathrm{L}$ of trimethylchlorosilane, the mixture stayed at $70^{\circ} \mathrm{C}$ for 30 min. GC-MS analyses were performed using the Agilent $6890 \mathrm{~N}$ gas chromatography coupled to a 5975 Agilent mass selective detector, equipped with a DB-1 column (J\&W: $30 \mathrm{~m} \times 0.25 \mathrm{~mm}$ i.d.; thickness, $0.25 \mu \mathrm{m}$ ), using the conditions described previously (Oliveira et al., 2006). Components were identified based on the comparison of their spectra with two spectral libraries (NIST/EPA/NIH Mass Spectral Database, US), the retention times and, in some cases by comparing their fragmentation profiles with published data. For quantitative analysis, GC-MS was calibrated with pure reference compounds, representative of the major lipophilic extractives components (namely hexadecanoic acid, 1-eicosanol, 16-hydroxyhexadecanoic acid, ferulic acid and stigmasterol), relative to tetracosane used as internal standards. For each sample two injections were performed and results represent the average of six injections. Between injections the variation was less than $6 \%$.

\subsection{Statistical analysis}

All chemical analysis and fractionation experiments were carried out at least twice and the results presented are the average of the values obtained for each fruit with a standard deviation lower than $6 \%$. The experimental data were statistically analyzed by one factor analysis of variance (ANOVA) to determine its significance at $P<0.05$, using the SPSS (Statistical Package for Social Science) version 15.0 for Windows.

\section{Results and discussion}

\subsection{Physical parameters}

The density of cherimoya fruit ranged from $0.88 \mathrm{~g} \mathrm{~cm}^{-3}$ to $1.11 \mathrm{~g} \mathrm{~cm}^{-3}$, without any important variation during the ripening period. Weight loss increased steadily during storage (Fig. 1) and at the end of the experiment fruit had lost around $9 \%$ in weight. No statistical relationship was found between the density and the fruit weight. Fruit weight loss during ripening was also reported by others in cherimoya (Alique et al., 1994), custard apple (Prasanna et al., 2000) and soursop (Lima et al., 2006), being mainly attributed to water loss through respiration, transpiration and ripening. Water content in 'Madeira' cherimoyas ranged between 73 and $83 \%$ similarly to what has been reported for custard apple, cherimoya, soursop and sugar apple (Pinto et al., 2005).

Penetration force used to evaluate cherimoya softening was higher than $63.6 \mathrm{~N}$ on the first two days after fruit harvest and decreased sharply at day 4 , reaching an average of $2.7 \mathrm{~N}$ at the end of storage (Fig. 1). At day 5 the fruit were over-ripe showing a softer texture that affects the quality for marketing. This enhanced rate of softening is in agreement with previous studies (Pareek et al., 


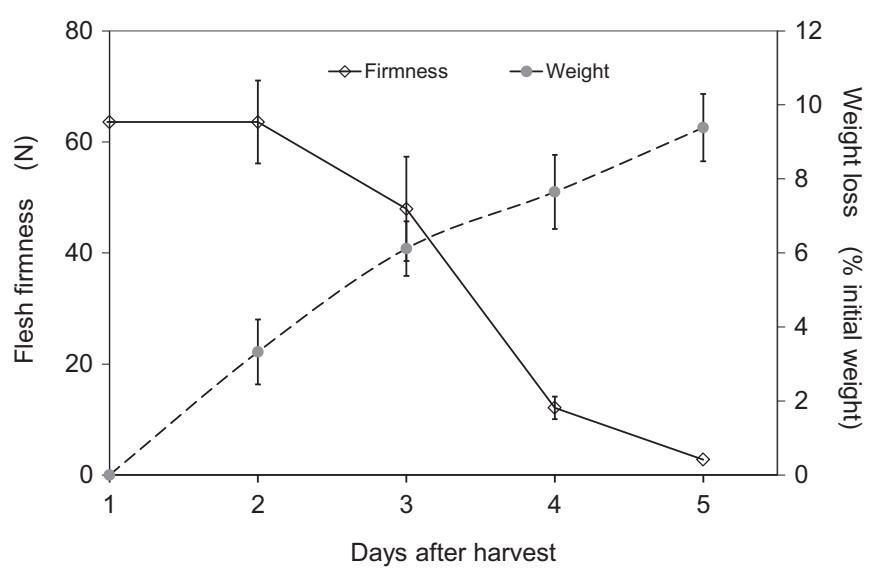

Fig. 1. Changes in flesh firmness and weight loss of cherimoya 'Madeira' during postharvest ripening. SDs $(n=3)$ are shown by vertical bars.

2011) and can be attributed to several physiological processes that proceed in the course of ripening.

\subsection{Chemical composition}

After fruit harvest, the content of chlorophyll slightly increased on the second day and decreased significantly $(P<0.05)$ on the third day of storage (Fig. 2). In fleshy fruit, chlorophyll breakdown is induced at the onset of ripening and may serve to indicate the degree of ripening (Barry, 2009). Chlorophyll degradation during fruit ripening might be due in part to chlorophyllase activity (Almela et al., 2000) which result in chlorophyll catabolites that contribute to alter aroma profiles (Barry, 2009) and might play a role as antioxidants (Müller et al., 2007).

The ash content was similar among fruit and during ripening $(P>0.05)$ (Table 1). Mineral composition showed that 'Madeira' cherimoyas are a good source of potassium but have moderate amounts of phosphorus, magnesium and calcium (Table 2). These results are consistent with those found by Leterme et al. (2006) for A. cherimola.

Total protein content decreased during the postharvest ripening (Table 1), although without significant differences $(P>0.05)$. Proteins provide amino acids, which are used as precursors of volatile compounds that are formed during the ripening process, giving typical aroma to fruit. Additionally, it can also provide nitrogen that might be reassimilated to form nitrogenous compounds such as polyamines that increase during the ripening of cherimoya (Escribano and Merodio, 1994). However, storage of A. cherimola

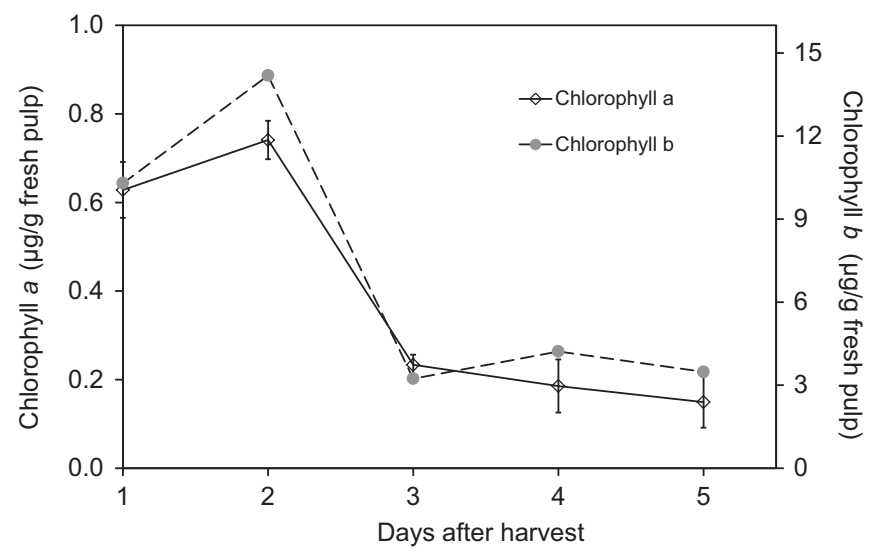

Fig. 2. Changes in chlorophyll content of cherimoya 'Madeira' fruit during postharvest ripening. SDs $(n=3)$ are shown by vertical bars.

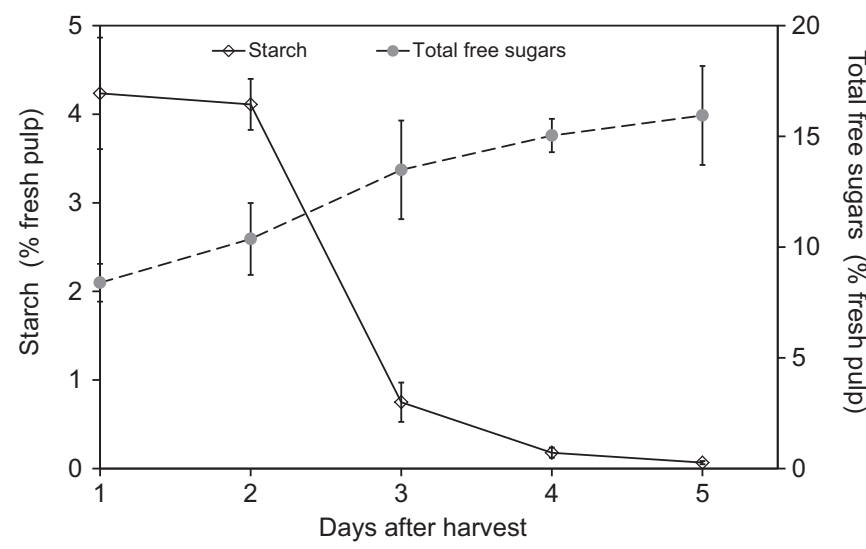

Fig. 3. Changes in starch and total free sugars of cherimoya 'Madeira' during postharvest ripening. SDs $(n=3)$ are shown by vertical bars.

'Fino de Jete' at $20^{\circ} \mathrm{C}$ showed an increase in the levels of proteins (Maldonado et al., 2002). This discrepancy might result from the postharvest physiology of both cultivars, the climatic conditions during the development and growth of cultivars, or the method used to measure the protein content.

Lignin content decreased slightly from the first to the second day in cherimoya fruit stored at room temperature (Table 1). From the third day onwards the increase in lignin was slow but not significant $(P>0.05)$. Lignin accumulation during cherimoya maturation might represent the presence of sclerenchyma as mesocarp encloses sclereids that contain substantial quantities of lignin. The accumulation of lignin during the ripening process of cherimoya 'Madeira' fruit was contrary of what was observed in cherimoya 'Fino de Jete' (Assis et al., 2001) and Psidium cattleyanum (Galho et al., 2007).

In unripe cherimoya, starch accounts for about $4 \%$ of the fresh pulp weight (Fig. 3). The starch content declined sharply during storage at room temperature and four days after harvest was negligible. A similar trend in starch breakdown during cherimoya ripening has previously been reported (Martinez et al., 1993; Gutiérrez et al., 1994). Statistical differences were found only on the second and third days of ripening $(P<0.05)$. The fast hydrolysis of starch was not paralleled by the accumulation rate of total free sugars. Therefore, besides starch being partially converted to free sugars, it is also transformed into organic acids, which is consistent with both increases in total free sugars (Fig. 3) and titratable acidity (Table 1).

Total sugars began to accumulate in unripe fruit and increased by almost $90 \%$ at the end of storage (day 5) when fruit were ripe (Fig. 3). However, the rise in free sugars was only significant between the first and second days $(P<0.05)$. The GC analyses of neutral sugars revealed that the predominant sugar in the mesocarp of cherimoya 'Madeira' was glucose (ca. 90\%). Altogether, the levels of free sugars present indicate that 'Madeira' is sweeter than other previously studied cultivars (Caldeira et al., 1995). The absence of monomers such as xylose, arabinose, ramnose, amongst others, allow us to conclude that there was not a considerable degradation of hemicelluloses during the ripening process, therefore the loss of firmness of the fruit perhaps cannot be connected to the alterations of these polymeric sugars.

The titratable acidity showed a considerable increase between days 2 and 3 after postharvest (Table 1). This increase in acidity was significant $(P<0.05)$ and can be ascribed to the production of organic acids, mainly malic acid (Alique et al., 1994), which contributes to the fruit aroma and influence perception of sweetness. At the end of the experiment the titratable acidity was two-fold higher than that measured on the first day. An increase in acidity was also reported in A. squamosa L. (Prasanna et al., 2000). 
Table 1

Chemical composition of 'Madeira' cherimoyas during postharvest ripening. Fruit were stored at $20-22^{\circ} \mathrm{C}$ after harvest.

\begin{tabular}{|c|c|c|c|c|c|}
\hline \multirow[t]{2}{*}{ Chemical composition ( $\left(100 \mathrm{~g}^{-1}\right.$ fresh pulp) } & \multicolumn{5}{|c|}{ Days after harvest } \\
\hline & 1 & 2 & 3 & 4 & 5 \\
\hline Ash & $0.884 \pm 0.174$ & $0.880 \pm 0.220$ & $0.885 \pm 0.229$ & $0.892 \pm 0.179$ & $0.836 \pm 0.186$ \\
\hline Protein & $1.523 \pm 0.191$ & $1.469 \pm 0.264$ & $1.511 \pm 0.159$ & $1.250 \pm 0.308$ & $1.196 \pm 0.130$ \\
\hline Lignin & $2.150 \pm 0.526$ & $1.969 \pm 0.222$ & $2.695 \pm 0.180$ & $2.759 \pm 0.272$ & $3.105 \pm 0.254$ \\
\hline Titratable acidity & $0.113 \pm 0.024$ & $0.101 \pm 0.009$ & $0.207 \pm 0.025$ & $0.227 \pm 0.033$ & $0.256 \pm 0.019$ \\
\hline Uronic acids & $0.065 \pm 0.010$ & $0.141 \pm 0.022$ & $0.186 \pm 0.035$ & $0.307 \pm 0.004$ & $0.324 \pm 0.032$ \\
\hline Lipophilic extractives & $0.324 \pm 0.032$ & $0.312 \pm 0.072$ & $0.347 \pm 0.072$ & $0.225 \pm 0.034$ & $0.221 \pm 0.017$ \\
\hline
\end{tabular}

Table 2

Mineral composition of 'Madeira' cherimoyas during postharvest ripening.

\begin{tabular}{|c|c|c|c|c|c|c|c|c|c|}
\hline \multirow[t]{2}{*}{ Days after harvest } & \multicolumn{9}{|c|}{ Mineral composition (mg $100 \mathrm{~g}^{-1}$ ) } \\
\hline & $\mathrm{K}$ & $\mathrm{P}$ & $\mathrm{Ca}$ & $\mathrm{Na}$ & $\mathrm{Mg}$ & $\mathrm{Fe}$ & $\mathrm{Cu}$ & $\mathrm{Zn}$ & $\mathrm{Mn}$ \\
\hline 1 & 406.8 & 17.9 & 11.3 & 15.9 & 177.0 & 0.12 & 0.06 & 0.13 & 0.31 \\
\hline 3 & 379.5 & 18.8 & 9.0 & 6.4 & 16.2 & 0.12 & 0.10 & 0.23 & 0.12 \\
\hline 4 & 411.0 & 35.6 & 31.6 & 23.4 & 29.8 & 0.26 & 0.14 & 0.23 & 0.40 \\
\hline 5 & 379.1 & 57.8 & 49.2 & 32.5 & 49.5 & 0.79 & 0.22 & 0.44 & 0.40 \\
\hline
\end{tabular}

Uronic acids increased during postharvest ripening with a significant rise $(P<0.05)$ on the second and fourth days (Table 1$)$. Uronic acid solubilization is coupled with the activity of pectolytic enzymes such as polygalacturonase (Sánchez et al., 1998) and $\beta$ galactosidase that increase continuously in A. muricata L. (Lima et al., 2006) during postharvest storage or pectin methylesterase believed to be involved in degradation of pectic cell wall components at the initial stages of ripening (Guadarrama and Andrade, 2012). Pectin solubilization has been observed in other fleshy fruit species as Carica papaya L. (Manrique and Lajolo, 2004) and Prunus persica L. Batsch (Ghiani et al., 2011) contributing to the softening mechanism.

\subsection{Characterization of the lipophilic extractives}

The lipid metabolism changed during fruit ripening as the lipophilic extractives decreased from $0.324 \mathrm{~g}$ per $100 \mathrm{~g}$ of fresh pulp in the first day to $0.221 \mathrm{~g}$ per $100 \mathrm{~g}$ of fresh pulp in the fourth day after harvest (Table 1 ), yet this reduction was not statistically different $(P>0.05)$. Lipid composition of fruit especially fatty acids ( $\alpha$-linolenic and linoleic acids), is important due to its health potential as it prevents, delay, or treat chronic and acute diseases, such as cancer, cardiovascular diseases, osteoporosis, cholesterol and immune disorders (Chen et al. 2013).

Table 3

Compounds ( $\mathrm{mg}$ of compound per kg of dry material) identified in the dichloromethane extracts of 'Madeira' cherimoyas during postharvest ripening.

\begin{tabular}{|c|c|c|c|c|c|}
\hline \multirow[t]{2}{*}{ Compound (mg kg ${ }^{-1}$, dry material) } & \multicolumn{5}{|c|}{ Days after harvest } \\
\hline & 1 & 2 & 3 & 4 & 5 \\
\hline Fatty acids & 2770 & 2130 & 1771 & 1116 & 868 \\
\hline Saturated & 1497 & 1180 & 1144 & 626 & 573 \\
\hline Pentadecanoic acid & 7 & 1 & 2 & 2 & n.d. \\
\hline Palmitic acid & 866 & 699 & 567 & 322 & 269 \\
\hline Heptadecanoic acid & 29 & 21 & 22 & 11 & 9 \\
\hline Octadecanoic acid & 142 & 94 & 98 & 48 & 52 \\
\hline Nonadecanoic acid & n.d. & 5 & n.d. & n.d. & 2 \\
\hline Hexadecanedioic acid & 45 & 37 & 45 & 29 & 24 \\
\hline Eicosanoic acid & 5 & n.d. & n.d. & n.d. & n.d. \\
\hline Docosanoic acid & 34 & 26 & 15 & 8 & 3 \\
\hline Tricosanoic acid & 115 & 119 & 129 & 54 & 77 \\
\hline Tetracosanoic acid & 254 & 23 & 21 & n.d. & n.d. \\
\hline Pentacosanoic acid & n.d. & 155 & 245 & 152 & 137 \\
\hline Unsaturated & 1273 & 950 & 627 & 490 & 295 \\
\hline Palmitelaidic acid & 8 & 6 & 5 & 2 & n.d. \\
\hline Oleic acid (cis or trans) & 180 & 238 & 146 & 114 & 135 \\
\hline Linoleic acid & 683 & 423 & 328 & 183 & 95 \\
\hline$\alpha$-Linolenic acid & 502 & 283 & 148 & 191 & 65 \\
\hline Sterols & 1431 & 1457 & 1292 & 876 & 1216 \\
\hline Campesterol & 154 & 156 & 142 & 96 & 134 \\
\hline Stigmasterol & 238 & 240 & 248 & 162 & 224 \\
\hline Sitosterol & 934 & 997 & 902 & 564 & 788 \\
\hline Isofucosanol or avenasterol & 105 & 64 & n.d. & 54 & 70 \\
\hline Long chain aliphatic alcohols & 49 & 65 & 62 & 120 & 44 \\
\hline 1-Octadecanol & n.d. & 2 & 5 & 83 & n.d. \\
\hline 1-Docosanol & 15 & 8 & 13 & 3 & 5 \\
\hline 1-Tetracosanol & 25 & 55 & 40 & 34 & 34 \\
\hline 1-Octacocanol & 9 & n.d. & 4 & n.d. & 5 \\
\hline$\delta$-Tocopherol & 34 & 12 & 32 & 5 & n.d. \\
\hline
\end{tabular}

n.d.: not detected. 
The analyses by GC-MS revealed that the quantities of lipophilic extractives varied as fruit ripen and were mainly formed by fatty acids and sterols (Table 3). Fatty acids accounted for $41-65 \%$ of the total extractives. Among the saturated fatty acids palmitic, pentacosanoic, tricosanoic and octadecanoic acids were predominant (Table 3). $\alpha$-Linolenic acid (omega-3) and linoleic acid (omega6 ) represented $8-18 \%$ and $11-25 \%$, respectively, of the total fatty acids content. During cherimoya ripening the saturated and unsaturated fatty acids decreased from 1497 to $573 \mathrm{mg} \mathrm{kg}^{-1}$ and 1273 to $295 \mathrm{mg} \mathrm{kg}^{-1}$ of pulp, respectively. This reduction could be due to the degradative lipolytic enzymes (Paliyath and Thompson, 1987) that are able to degrade endogenous lipids, thus changing the lipid bilayer and accelerating permeability in senescing membranes. The chemical changes in the lipid bilayer might include the loss of phospholipids and fatty acids, and an increase in the sterol: fatty acid ratio. In the present study the sterol: fatty acid ratio increased from 0.52 to 1.40 , values similar to those obtained for 'Fino de Jete' cherimoyas (Gutiérrez et al., 2005).

The sterols were the second largest family in the lipophilic extractives comprising $33-57 \%$ of the total extracts. Sitosterol (65-70\% of total sterols), stigmasterol (17-19\%) and campesterol (about 11\%) were the prevalent sterols present in cherimoya 'Madeira'. The sterol composition of this cultivar can contribute to the intake of natural phytosterols in the human diets, which appear to be a practical and safe option for reducing cholesterol levels in the population (Quílez et al., 2003).

The percentage of long chain aliphatic alcohols in the lipophilic extracts ranged from 1.1 to $5.7 \%$ 1-tetracosanol being the most predominant (28-85\% of the total of this family) followed by 1 docosanol, with values ranging between 3 and 31\% (Table 3). 1-Octadecanol increased significantly at day 4 , accounting for $69 \%$ of the total long chain aliphatic alcohols. It may be assumed that this increase at day 4 might coincide with the production of ethylene, as this compound is necessary for the coordination and completion of ripening in climacteric fruit (Giovannoni, 2001). Reports on the role of long chain aliphatic alcohols in human health suggest a decrease in the low-density lipoprotein cholesterol and an increase in the high-density lipoprotein cholesterol (Hargrove et al., 2004).

In this study, only $\delta$-tocopherol was detected and decreased with fruit maturation, being almost absent around day 4 . Like cherimoya, this phenomenon has been described for other climacteric fruit such as tomatoes (Abushita et al., 1997) and grapes (El-Shami et al., 2001). The reduction of $\delta$-tocopherol might be related to the transformation into $\alpha$-tocopherol (Schultz, 1990), although the $\alpha$-tocopherol was not detected in any of the samples analyzed. Despite the low content of tocopherol in cherimoya, their consumption together with other plant-derived foods provide a significant source of vitamin $\mathrm{E}$, which has been associated with the prevention of cardiovascular diseases, cancer, inflammatory diseases, neurological disorders, cataract and age-related macular degeneration, as well as to the maintenance of the immune system (Bramley et al., 2000).

\section{Conclusion}

The results showed that the quality attributes and nutritional contents of 'Madeira' cultivar changed significantly during postharvest ripening, with substantial changes occurring on the third day. The outcomes of this study emphasize 'Madeira' as an excellent nutrient resource. The lipophilic extractives data are a relevant contribution for the value of this cherimoya cultivar as source of highly valuable phytochemicals such as omega- 3 and omega- 6 fatty acids, and sterols, which are well known for their beneficial impacts on health.
Considering the importance of texture in consumer acceptability of fruit quality further studies in fruit physiology should be explored for desired postharvest fruit handling or suppressing expression of specific enzymes that contribute to softening.

\section{References}

Abushita, A.A., Hebshi, E.A., Daood, H.G., Biacs, P.A., 1997. Determination of antioxidant vitamins in tomatoes. Food Chem. 60, 207-212.

Alique, R., Oliveira, G.S., 1994. Changes in sugars and organic acids in cherimoya (Annona cherimola Mill.) fruit under controlled atmosphere storage. J. Agric. Food Chem. 42, 799-803.

Alique, R., Zamorano, J.P., Calvo, M.L., Merodio, C., De La Plaza, J.L., 1994. Tolerance of cherimoya (Annona cherimola Mill.) to cold tolerance. J. Am. Soc. Hort. Sci. 119, 524-528.

Almela, L., Fernández-López, J.A., Roca, M.J., 2000. High-performance liquid chromatographic screening of chlorophyll derivatives produced during fruit storage. J. Chromatogr. A 870, 483-489.

AOAC, 2000. Official method of analysis 934.01, vol. I., 17th ed. Association of Official Analytical Chemists, Inc., Maryland, USA.

Assis, J.S., Maldonado, R., Muñoz, T., Escribano, M.I., Merodio, C., 2001. Effect of high carbon dioxide concentration on PAL activity and phenolic contents in ripening cherimoya fruit. Postharvest Biol. Technol. 23, 33-39.

Barry, C.S., 2009. The stay-green revolution: recent progress in deciphering the mechanisms of chlorophyll degradation in higher plants. Plant Sci. 176, 325-333.

Blakeney, A.B., Harris, P.J., Henry, R.J., Stone, B.A., 1983. A simple and rapid preparation of alditol acetates for monosaccharide analysis. Carbohyd. Res. 113, 291-299.

Bramley, P.M., Elmadfa, I., Kafatos, A., Kelly, F.J., Manios, Y., Roxborough, H.E., Schuch, W., Sheehy, P.J.A., Wagner, K.-H., Vitamin, E., 2000. J. Sci. Food Agr. 80, 913-938

Brummell, D.A., 2006. Cell wall disassembly in ripening fruit. Funct. Plant Biol. 33 103-119.

Caldeira, J.J., Araújo, J.A., Nunes, R., 1995. Caracterização física e química dos frutos de três variedades de anonas cultivadas na Madeira. Rev. Cien. Agr. 18, 57-67.

Chen, B., McClements, D.J., Decker, E.A., 2013. Design of foods with bioactive lipids for improved health. Annu. Rev. Food Sci. Technol. 4, 35-56.

Dubois, M., Gilles, K.A., Hamilton, J.K., Rebers, P.A., Smith, F., 1956. Colorimetric method for determination of sugars and related substances. Anal. Chem. 28 350-356.

El-Shami, S.M., Hassanein, M.M.M., El-Mallah, M.H., 2001. Studies on changes in lipid profiles of new varieties of rape during seed maturation. Grasas Aceites 52, 94-103.

Escribano, M.I., Merodio, C., 1994. The relevance of polyamine levels in cherimoya (Annona cherimola Mill.) fruit ripening. J. Plant Physiol. 143, 207-212.

FAO (Food and Agriculture Organization), 2012. http://faostat.fao.org/

Galho, A.D., Lopes, N.F., Bacarin, M.A., Lima, M.G.S., 2007. Chemical composition and growth respiration in Psidium cattleyanum during the development cycle. Rev. Bras. Frutic. 29, 61-66.

Ghiani, A., Onelli, E., Aina, R., Cocucci, M., Citterio, S., 2011. A comparative study of melting and non-melting flesh peach cultivars reveals that during fruit ripening endo-polygalacturonase (endo-PG) is mainly involved in pericarp textural changes, not in firmness reduction. J. Exp. Bot. 62, 4043-4054.

Giovannoni, J., 2001. Molecular biology of fruit maturation and ripening. Annu. Rev. Plant Physiol. Plant Mol. Biol. 52, 725-749.

Goñi, O., Muñoz, M., Ruiz-Cabello, J., Escribano, M.I., Merodio, C., 2007. Changes in water status of cherimoya fruit during ripening. Postharvest Biol. Technol. 45, $147-150$.

Guadarrama, A., Andrade, S., 2012. Physical, chemical and biochemical changes of sweetsop (Annona squamosa L.) and golden apple (Spondias citherea Sonner) fruits during ripening. J. Agric. Sci. Technol. B 2, 1148-1157.

Gutiérrez, M., Mar Sola, M., Pascual, L., Vargas, A.M., 1994. Postharvest changes of sugar concentrations in chilled-injured cherimoya (Annona cherimola Mill.). J. Plant Physiol. 143, 27-32.

Gutiérrez, M., Mar Sola, M., Vargas, A.M., 2005. Fatty acid composition of phospholipids in mesocarp of cherimoya fruit during ripening. Food Chem. 90, 341-346.

Hargrove, J.L., Greenspan, P., Hartle, D.K., 2004. Nutritional significance and metabolismm of very long chain fatty alcohols and acids from dietary waxes. Exp. Biol. Med. 229, 215-226.

Leterme, P., Buldgen, A., Estrada, F., Londoño, A.M., 2006. Mineral content of tropica fruits and unconventional foods of the Andes and the rain forest of Colombia. Food Chem. 95, 644-652.

Lichtenthaler, H.K., 1987. Chlorophylls and carotenoids: pigments of photosynthetic biomembranes. Method Enzymol. 148, 331-382.

Lima, M.A.C., Alves, R.E., Filgueiras, H.A.C., 2006. Changes related to softening of soursop during postharvest maturation. Pesqui. Agropecu. Bras. 41, 1707-1713.

Maldonado, R., Molina-Garcia, A.D., Sanchez-Ballesta, M.T., Escribano, M.I., Merodio, C., 2002. High $\mathrm{CO}_{2}$ atmosphere modulating the phenolic response associated with cell adhesion and hardening of Annona cherimola fruit stored at chilling temperature. J. Agric. Food Chem. 50, 7564-7569.

Manrique, G.D., Lajolo, F.M., 2004. Cell-wall polysaccharide modifications during postharvest ripening of papaya fruit (Carica papaya). Postharvest Biol. Technol. $33,11-26$ 
Martinez, G., Serrano, M., Pretel, M.T., Riquelme, F., Romojaro, F., 1993. Ethylene biosynthesis and physico-chemical changes during fruit ripening of cherimoya Annona cherimola, Mill. J. Hort. Sci. 684, 477-483.

Müller, T., Ulrich, M., Ongania, K.H., Krautler, B., 2007. Colorless tetrapyrrolic chlorophyll catabolites found in ripening fruit are effective antioxidants. Angew. Chem. Int. Ed. 46, 8699-8702

Oliveira, L., Freire, C.S.R., Silvestre, A.J.D., Cordeiro, N., Torres, I.C., Evtuguin, D., 2006 Lipophilic extractives from different morphological parts of banana plant Dwarf Cavendish. Ind. Crop. Prod. 23, 201-211.

Paliyath, G., Thompson, J.E., 1987. Calcium and calmodulin regulated breakdown of phospholipid by microsomal membranes from bean cotyledons. Plant Physiol. 83, 63-68.

Pareek, S., Yahia, E.M., Pareek, O.P., Kaushik, R.A., 2011. Postharvest physiology and technology of Annona fruits. Food Res. Int. 44, 1741-1751.
Pinto, A.C.Q., Cordeiro, M.C.R., Andrade, S.R.M., Ferreira, F.R., Filgueiras, H.A.C., Alves, R.E., Kinpara, D.I., 2005. Annona species. International Centre for Underutilised Crops, University of Southampton, Southampton, UK.

Prasanna, K.N.V., Rao, D.V.S., Krishnamurthy, S., 2000. Effect of storage temperature on ripening and quality of custard apple (Annona squamosa L.) fruits. J. Hort. Sci. Biotechnol. 75, 546-550.

Quílez, J., García-Lorda, P., Salas-Salvadó, J., 2003. Potential uses and benefits of phytosterols in diet: present situation and future directions. Clin. Nutr. 22, 343-351.

Sánchez, J.A., Zamorano, J.P., Alique, R., 1998. Polygalacturonase, cellulase and invertase activities during cherimoya fruit ripening. J. Hort. Sci. Biotechnol. 73, 87-92.

Schultz, G., 1990. Biosynthesis of $\alpha$-tocopherol in chloroplasts of higher plants. Eur. J. Lipid Sci. Technol. 92, 86-91. 